\title{
Nanophotonics
}

SPIEDigitalLibrary.org/jnp

\section{So long, farewell, auf wiedersehen, goodbye!}

Akhlesh Lakhtakia 


\title{
So long, farewell, auf wiedersehen, goodbye!
}

\author{
Akhlesh Lakhtakia \\ Editor-in-Chief
}

Never intensely religious and now indifferent to religion for over three decades, I have been relentlessly pursued by religion all my life. Every atom of India, where I was born and raised, is steeped in religious lore. At temples that are liberally sprinkled all over, devotees let the bells rest only at the peak of the night. Most days in every neighborhood, a Brahmin recounts a scriptural saga on a loudspeaker. Several times during the day, the muezzin issues his call to the faithful, also on a loudspeaker. In this atmosphere, which is quite often marred by clashes between the adherents of different religions, I went to college for five years in Varanasi, perhaps the holiest city for Hindus.

The USA is no less religious than India. Although religious fervor in the USA is not broadcast through public address systems, it emanates from numerous radio and television channels every Sunday morning. No politician, howsoever sinful otherwise, ends his or her speeches without a religious benediction; every coin and every banknote carries a theistic slogan; and religious presence in public spaces is continually dissected with a microtome in many judicial pronouncements. Therefore, not much changed for me when I went to graduate school for about four years in Salt Lake City, which houses the headquarters of the Mormon church, and later when I joined the Pennsylvania State University.

In 2010, I visited an Israeli university for two weeks and also spent a day in the West Bank. As in India, religion is ubiquitous in this land. Every historical site is emotionally connected to two or even three religions. My curiosity being of anthropological, architectural, and historical provenances, I went to the Wailing Wall and the Dome of the Rock in Jerusalem; the churches of annunciation in Nazareth, nativity in Bethlehem, and the holy sepulcher in Jerusalem; and the tombs of Abraham and Sara in Hebron.

I was most pleased to see the Mount of Olives where I recalled the Sermon on the Mount, arguably the most influential recorded speech in human history. As the sacred and the profane often mix well, there I was reminded of a bumper sticker that is commonplace in USA: "WWJD." The acronym stands for "What would Jesus do?"

During the last seven and a half years as the editor-in-chief of the Journal of Nanophotonics, I have had to often ask myself: WWJD?

The situations have been diverse. Let me provide an oft-repeated example: Most authors write an abstract either as an introduction to or as an advertisement of the full paper. Instead, an abstract must be written as a complete, although tiny, paper-with the supposition that the full paper accompanying it does not exist. The abstract must include the following components: a brief background, brief descriptions of methods and chief results, and significant conclusions. The WWJD moment comes when the authors of a submitted paper ignore detailed instructions to rewrite the abstract properly, quite possibly because it is viewed not as the most important part of a paper but as simply a ritual paragraph. I mutter "WWJD," often at the crack of dawn when peace and quiet reign supreme, and rewrite the abstract for the authors. Imagine my anguish when I later find out that the published abstract had my changes partially undone. Invoking WWJD, I resolve yet again not to stop editing abstracts.

Another example: The issue of appropriate coauthorship arises when I note that some coauthors have been thanked by another coauthor, usually the corresponding coauthor, in the acknowledgments. How can a person be a coauthor of a paper and still be thanked in the same paper? An incongruity is obvious. I counsel the corresponding coauthor to either remove the name of the thanked coauthor from the list of authors or remove the thanks for that coauthor from the acknowledgments. If the former course of action is chosen, I also request a letter of concurrence from the person whose name would be written off the list of coauthors. The WWJD moment comes when I encounter the same issue from the same corresponding coauthor for a paper submitted some months later.

My wife tells me that I am becoming more patient as time goes by. Certainly, every WWJD moment provides me a teaching opportunity. I teach myself to be kinder and gentler. 
Instead of stamping my feet on the floor like Rumpelstiltskin, I recall a mondegreen and laugh heartily for a short while. Laughter has made my outlook more positive. I am a happier person.

My happiness also stems from the solid foundations acquired by the Journal of Nanophotonics during the last 89 months. SPIE had decided in early 2006 that it would commence the publication of an online journal devoted to optics/photonics at the nanoscale. This was a progressive decision, since no journal was then positioned at the crossroads of nanotechnology and optics/photonics. Later that year, I was delighted to take on the role of editor-in-chief. The scope of the new journal was defined, an editorial board was assembled, brochures to announce the journal's launch in January 2007 were written and disseminated, and editorial policies were codified. Most importantly, SPIE staff spent countless hours, first to ensure a smooth deployment of an online portal for submission and reviewing activities, and then to publish accepted papers online. January 2007 came, and the journal was off with a running start.

The journal publishes regular papers and letters, along with special thematic sections guest edited by prominent researchers. Invited review papers are published as well. Occasionally, book reviews are published. These forms of communication are the arteries and veins of any technoscientific discipline. But researchers in one discipline must also communicate with researchers in other disciplines, public leaders and policy planners, and future researchers. Therefore, I was especially glad a couple of years later when several researchers enthusiastically responded to my calls to write short commentaries on exciting new developments in nanophotonics. These commentaries are made freely available to the general public in order to help us all prepare for a nanotechnological future.

As the Journal of Nanophotonics enters its eighth year of publication, it is not only an ever more vital member of the SPIE publishing program, but also firmly entrenched as the premier journal in nanophotonics. When I wrote this editorial, the Web of Knowledge had recorded the publication of 493 items in the journal. Of these, the five most cited papers are in the areas of absorption by silicon nanowire films, ${ }^{1}$ optical manipulation of nanoparticles,${ }^{2}$ photoluminescence from silicon nanostructures, ${ }^{3}$ surface multiplasmonics, ${ }^{4}$ and plasmon-assisted photonics. ${ }^{5}$ This brief list of topics indicates that the journal's influence in nanophotonics shall continue to grow. Papers on metamaterials began to be accepted three years ago for publication, and these too shall have significant impact in the coming years. Several papers published in the journal have been highlighted during the last two years in SPIE Professional.

As the journal's future appears bright, "the time has come" for me to take the advice of the immortal Dr. Seuss and step down as the editor-in-chief of the Journal of Nanophotonics. Starting a new journal for a learned society and mooring it strongly in the research arena have been wonderful experiences for me. I have learned a lot about the psychology of researchers, both old and young, from countries with currently longstanding technoscientific traditions, as well as from those where technoscientific cultures are still forming. All associate editors of this journal are no longer just professional colleagues but have become my friends, and there is no wealth that can surpass a true friendship. The journal staff at SPIE headquarters is dedicated to the service of the technoscientific research community, and has been a real asset to me.

But the continued vitality of this journal requires a fresh steward to take over from its founding editor-in-chief. I am confident that my successor, Prof. Ali Adibi of Georgia Tech, will bring a burst of new energy in January 2014 to this journal and the community of its authors and readers.

Oh, I forgot to tell you the mondegreen. It is: "Lead on, you kinky turtle!" Google it and laugh aloud.

\section{References}

1. L. Tsakalakos et al., "Strong broadband optical absorption in silicon nanowire films," J. Nanophotonics 1, 013552 (2007), http://dx.doi.org/10.1117/1.2768999.

2. M. Dienerowitz, M. Mazilu, and K. Dholakia, "Optical manipulation of nanoparticles: a review," J. Nanophotonics 2, 021875 (2008), http://dx.doi.org/10.1117/1.2992045. 
3. A. Sa'ar, "Photoluminescence from silicon nanostructures: The mutual role of quantum confinement and surface chemistry," J. Nanophotonics 3, 032501 (2009), http://dx.doi.org/10 $.1117 / 1.3111826$.

4. M. A. Motyka and A. Lakhtakia, "Multiple trains of same-color surface plasmon-polaritons guided by the planar interface of a metal and a sculptured nematic thin film," J. Nanophotonics 2, 021910 (2008), http://dx.doi.org/10.1117/1.3033757.

5. S. A. Kalele et al., "Plasmon-assisted photonics at the nanoscale," J. Nanophotonics 1, 012501 (2007), http://dx.doi.org/10.1117/1.2748429. 